Research

\title{
Macromolecular and elemental composition analysis and extracellular metabolite balances of Pichia pastoris growing at different oxygen levels
}

\author{
Marc Carnicer ${ }^{1}$, Kristin Baumann ${ }^{1}$, Isabelle Töplitz ${ }^{1,4,5}$, Francesc Sánchez- \\ Ferrando ${ }^{2}$, Diethard Mattanovich ${ }^{3,4}$, Pau Ferrer ${ }^{1}$ and Joan Albiol*1
}

Address: ${ }^{1}$ Departament d'Enginyeria Química, Escola d'Enginyeria, Universitat Autònoma de Barcelona, 08193-Bellaterra (Cerdanyola del Vallès), Spain, ${ }^{2}$ Departament de Química, Universitat Autònoma de Barcelona, 08193-Bellaterra (Cerdanyola del Vallès), Spain, ${ }^{3}$ Department of Biotechnology, BOKU-University of Natural Resources and Applied Life Sciences, Vienna, Austria, ${ }^{4}$ School of Bioengineering, University of Applied Sciences FH-Campus Wien, Vienna, Austria and ${ }^{5}$ Current address: Ludwig Boltzmann Institute for Cancer Research (LBI-CR), Vienna, Austria

Email: Marc Carnicer - marc.carnicer@uab.cat; Kristin Baumann - kristin.baumann@uab.cat;

Isabelle Töplitz - isabelle.toeplitz@meduniwien.ac.at; Francesc Sánchez-Ferrando - paco.sanchez@uab.cat;

Diethard Mattanovich - diethard.mattanovich@boku.ac.at; Pau Ferrer - pau.ferrer@uab.cat; Joan Albiol* - joan.albiol@uab.cat

* Corresponding author

Published: 9 December 2009

Microbial Cell Factories 2009, 8:65 doi:10.1 186/1475-2859-8-65
Received: 8 September 2009

Accepted: 9 December 2009

This article is available from: http://www.microbialcellfactories.com/content/8/1/65

(C) 2009 Carnicer et al; licensee BioMed Central Ltd.

This is an Open Access article distributed under the terms of the Creative Commons Attribution License (http://creativecommons.org/licenses/by/2.0), which permits unrestricted use, distribution, and reproduction in any medium, provided the original work is properly cited.

\begin{abstract}
Background: Analysis of the cell operation at the metabolic level requires collecting data of different types and to determine their confidence level. In addition, the acquired information has to be combined in order to obtain a consistent operational view. In the case of Pichia pastoris, information of its biomass composition at macromolecular and elemental level is scarce particularly when different environmental conditions, such as oxygen availability or, genetic backgrounds (e.g. recombinant protein production vs. non production conditions) are compared.

Results: $P$. pastoris cells growing in carbon-limited chemostat cultures under different oxygenation conditions $\left(\% \mathrm{O}_{2}\right.$ in the bioreactor inlet gas: $21 \%, 11 \%$ and $8 \%$, corresponding to normoxic, oxygen-limiting and hypoxic conditions, respectively), as well as under recombinant protein (antibody fragment, Fab) producing and non-producing conditions, were analyzed from different points of view. On the one hand, the macromolecular and elemental composition of the biomass was measured using different techniques at the different experimental conditions and proper reconciliation techniques were applied for gross error detection of the measured substrates and products conversion rates. On the other hand, fermentation data was analyzed applying elemental mass balances. This allowed detecting a previously missed by-product secreted under hypoxic conditions, identified as arabinitol ( $a k a$. arabitol). After identification of this C5 sugar alcohol as a fermentation by-product, the mass balances of the fermentation experiments were validated.

Conclusions: After application of a range of analytical and statistical techniques, a consistent view of growth parameters and compositional data of $P$. pastoris cells growing under different oxygenation conditions was obtained. The obtained data provides a first view of the effects of oxygen limitation on the physiology of this microorganism, while recombinant Fab production seems to have little or no impact at this level of analysis. Furthermore, the results will be highly useful in other complementary quantitative studies of $P$. pastoris physiology, such as metabolic flux analysis.
\end{abstract}




\section{Background}

The operation of living cells can be viewed as a complex network of interacting biomolecules. In order to gain a deeper understanding of the cell's response to different environmental conditions, a number of high throughput analyses are nowadays performed, covering different cellular levels such as the genome, transcriptome, proteome, metabolome and fluxome [1-3]. Metabolic flux analysis (MFA), provides a highly informative view of the physiological cell status under a given environmental condition or genetic background. Genome-scale in silico metabolic models are nowadays being built for a number of microorganisms to this purpose $[4,5]$. Validation and practical application of such complex models require obtaining reliable experimental data on a number of metabolic fluxes, among which those related to biosynthesis precursors for cell constituents play a key role [6,7]. Considering that cells are made up of different biopolymers and macromolecules, knowledge of their composition and quantity becomes essential for determination of the metabolic fluxes of biosynthetic precursors, as well as for any other metabolic or energetic analysis. For instance, determination of metabolic fluxes from the measured ${ }^{13} \mathrm{C}$ isotopomer distribution of proteinogenic amino acids [8] requires to measure not only the external metabolic fluxes of the cell, but also the amino acid composition of the proteins being produced so that drain of biosynthetic precursors towards biomass synthesis can be properly taken into account. Availability of such molecular compositional data is scarce or inexistent for a specific strain or species and growth condition, particularly in non-model organisms as $P$. pastoris. Previous application of the above mentioned methodologies on Pichia pastoris $[9,10]$ has mainly relied on available compositional data from a related species such as $S$. cerevisiae [3].

Determination of biomass molecular composition usually relies on application of different analytical techniques for the range of biochemical compounds considered, each one with its own sensitivity, interferences and confidence level; moreover, some of them providing redundant information. Application of the numerical techniques for metabolic flux analysis requires the quantitative determination of a consistent biomass composition. For example, percentages of macromolecular components analysed by different methods must ideally combine to $100 \%$ and the addition of their elemental compositions must combine to give the measured elemental composition. Also, confidence intervals for all the elements and components have to be calculated. To such purpose, statistical techniques have been developed [11] allowing to obtain the best estimation of such consistent biomass composition and the corresponding confidence intervals. Furthermore, such consistency should be extended to the measured input/output fluxes of the cells in order to verify that the system operates as expected $[12,13]$.

In this study, a consistent description of the biomass composition of $P$. pastoris has been obtained for different oxygenation conditions, as well as under recombinant protein producing and non-producing backgrounds. In addition, a consistency analysis of the input and output extracellular metabolic fluxes has been used to identify the production of an unexpected by-product, which has been subsequently identified as arabinitol. Besides, multilevel analyses using $P$. pastoris-specific DNA arrays and proteomic techniques have been performed in parallel to this baseline study [14].

\section{Results and discussion}

In this study, the differences in biomass composition are evaluated for two different $P$. pastoris strains, namely the $\mathrm{X}$-33-derived strain expressing the human antibody fragment Fab 3H6 [15] and a control X-33 strain transformed with the corresponding mock expression vector. For these two strains, three different oxygenation conditions (normoxic, oxygen-limited and hypoxic, corresponding to $\mathrm{O}_{2}$, concentrations in the bioreactor inlet gas of about $21 \%$, $11 \%$ and $8 \%$ of $\mathrm{O}_{2}$, respectively) were assayed in carbonlimited continuous cultures using glucose as carbon source. As previsouly described [16], P. pastoris shows a fully respirative metabolism under normoxic conditions, a shift towards respirofermentative metabolism can be observed under oxygen-limiting conditions, and a clearly respirofermentative metabolism is shown under hypoxic conditions. For each case, the different biomass composition analyses described in the materials and methods section were performed. At this point, the different biomass chemical analyses can be considered at two levels, resulting either in an elemental or a molecular description of the biomass constituents. The variations and similarities observed at these levels were further used to propose a consensus composition for each case.

\section{Molecular biomass composition}

At the molecular level, and for simplicity, the biomass composition is usually described in terms of major groups of biomass constituents, namely proteins, carbohydrates, lipids, DNA and RNA [13]. In some cases, each of these groups is further analyzed for their major constituents. This procedure allows determining, not only their mass fractions and consensus global carbon molecular formula, but also which particular precursors and corresponding amounts are required for their biosynthesis.

\section{Proteins and amino acid content}

Proteins are one of the major constituents of the biomass, usually representing around $50 \%$ of the dry weight of a 
microorganism [13]. Consequently, detailed knowledge of their composition is important for any metabolic and energetic calculations. As there are virtually no data on the amino acid composition of $P$. pastoris available, determination of this composition was performed for both strains at each of the tested oxygenation condition, as shown in Table 1 . These analyses revealed that, for a given oxygenation condition, differences between the control and the Fab-expressing strain were, for most of the amino acids, below $9 \%$. Some exceptions were found for cysteine (for which, one of the analysis resulted in amounts below detection limits), ornithine, methionine and valine. Nevertheless, these differences were apparently not correlated to changes in experimental conditions (oxygenation level or Fab production). Therefore, it was considered that the control and Fab-expressing strains did not show significant differences in their amino acid composition for any of the oxygenation conditions. Consequently, average amino acid composition values of $P$. pastoris (shown in Table 2) for each oxygenation condition were considered for further compositional data calculations. Notably, values given in Table 2, suggest that some amino acids (e.g. Glx, Orn, Arg) appeared to follow a consistent tendency to decrease as oxygen availability was reduced, while others seemed to remain at the same level (e.g. Thr, Trp, His, Met). Nevertheless, considering the standard deviations of the analysis (see Materials and Methods section), further experimental data would be required to confirm these tendencies. The amount of precursors consumed to produce cell proteins with the measured composition (mols of each amino acid per 100 mols of amino acids), shown in Figure 1, was calculated taking into account the main $P$. pastoris biosynthetic routes for the amino acids synthesis; these were revised on the basis of its recently published genome sequence $[17,18])$. Grouping of amino acids, according to their common precursor in the central carbon metabolism (Figure 1), revealed that the amino acids precursor requirements showed a correlation with the variation of oxygen availability, with the exception of the precursors consumed from the pentose phosphate pathway. Following this observation, it was considered that those variations would have an impact on the calculated metabolic fluxes and, therefore, it was decided to adopt a different biomass composition for each of the three oxygenation conditions. In addition, data shown in Tables 1 and 2 reveal that the measured amino acid composition for $P$. pastoris was significantly different to the previously published amino acid composition of S. cerevisiae [11]. Interestingly, Orn presents several fold changes in terms of relative amounts between the two yeasts, while Arg, Ile, Leu, Val, Gly, Met and Ser show relative abundance values with a more than $10 \%$ variation from the $S$. cerevisiae data. These results justify the adoption of a specific amino acid composition for $P$. pastoris instead of the previously available compositional data from $S$. cerevisiae.

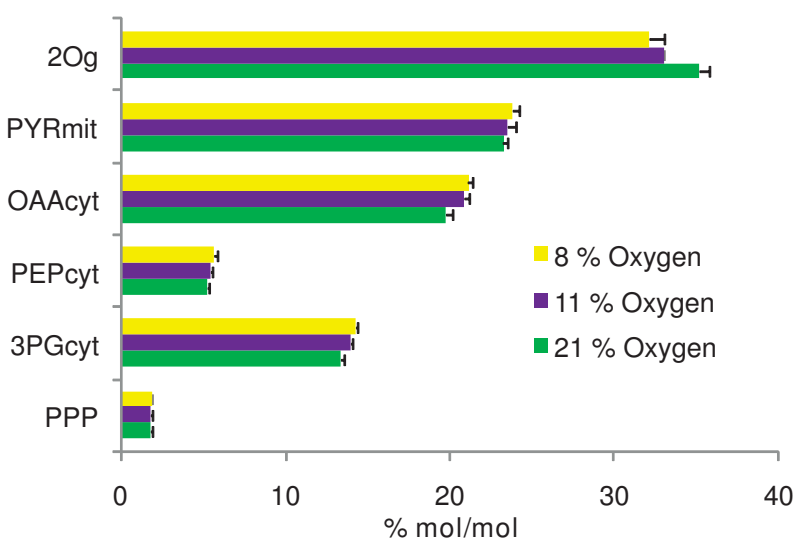

\section{Figure I}

Amount of key precursors required for protein generation at each experimental condition. Using the average amino acid compositional data provided in Table 2, a calculation of the amounts of precursors consumed for protein generation was done. Nomenclature: $\alpha$-keto-glutarate: 2Og, mitochondrial pyruvate: PYRmit, cytosolic oxalacetate: OAAcyt, cytosolic phosphoenolpyruvate: PEPcyt, cytosolic 3phophoglycerate: 3PGcyt, pentose phosphate pathway: PPP.

Total cell protein content (Figure 2 (top left)) was measured using two different methods. A first approximation was based on the sum of amounts of each amino acid obtained in the amino acid compositional analysis. Since this analytical technique involves an acid hydrolysis step of cell protein (see Materials and Methods section), it was expected that the value obtained by adding all the amino acids amounts should be on the lower margin. In the second approximation, the protein content of the biomass was measured using the widely used Lowry method, using bovine serum albumin as standard. The different values obtained and the standard deviation of the different analytical approaches made it difficult to calculate a proper value for the protein content for each case. Therefore, total protein content values given by the two methods, together with their confidence intervals were used in the data reconciliation step. This procedure allows calculating the total protein content that best agrees with all the information available. The reconciled values indicated an increase in the global protein content correlated with the oxygen limitation (see below: Reconciled biomass composition). In addition, the amount of intracellular and extracellular heterologous protein was measured in the Fab-expressing strain. Figure 3 shows that the amount of extracellular Fab increases when the oxygen concentration in the inlet gas decreases down to about $8 \%$, in accordance with previous results [14]. At the same time, intracellular Fab content (which can also be considered as part of the total protein content) also increased significantly when reducing the oxygen availability. Nevertheless, further detailed studies 


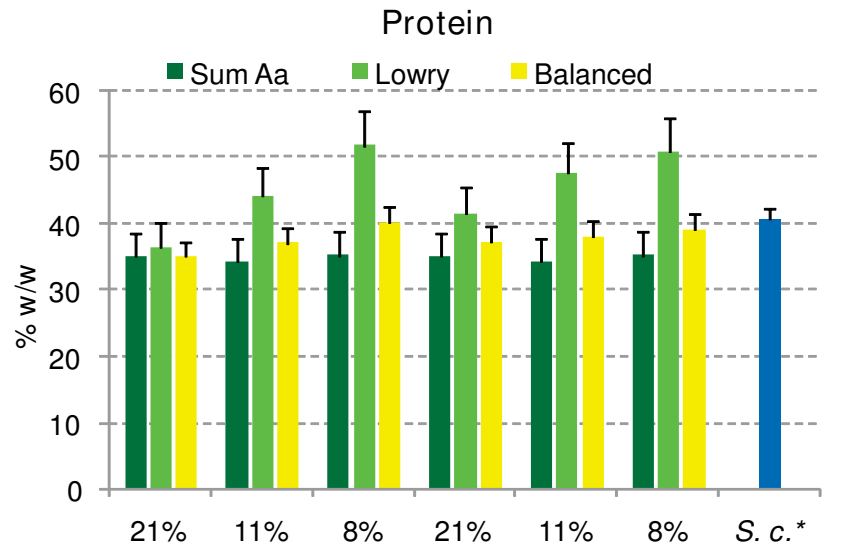

Fab-expressing Strain Control Strain

\section{RNA}

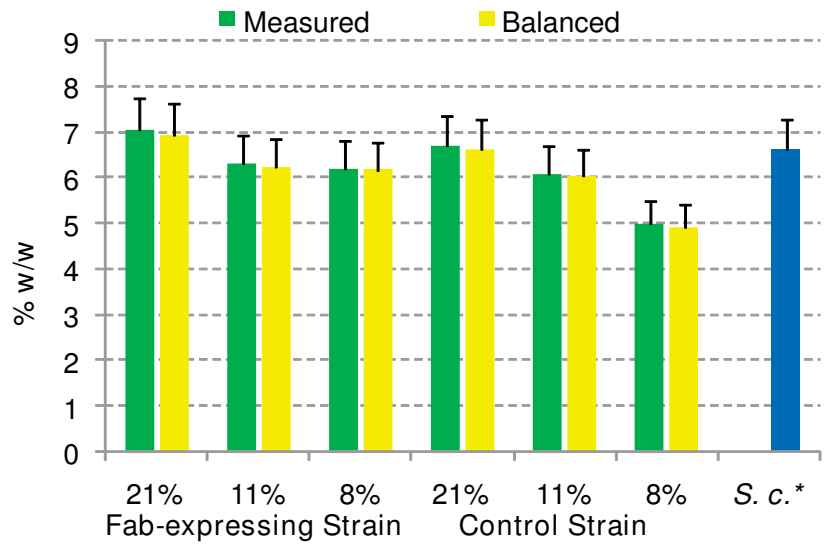

Carbohydrate

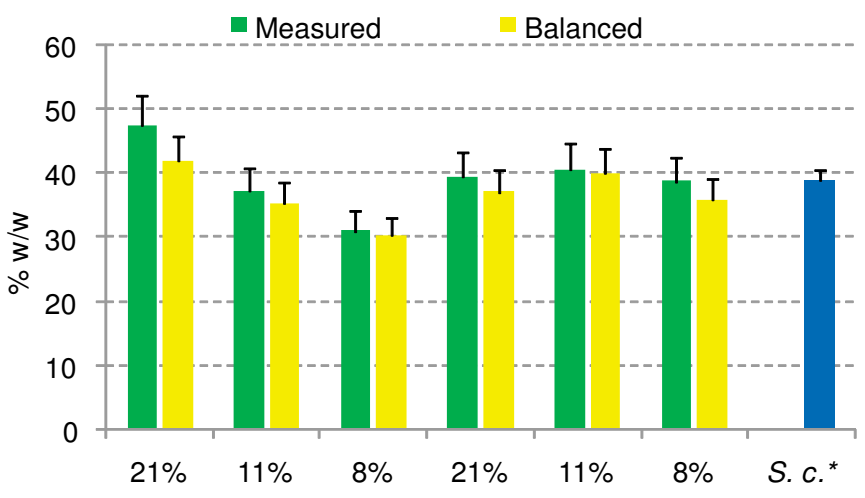

Fab-expressing Strain Control Strain

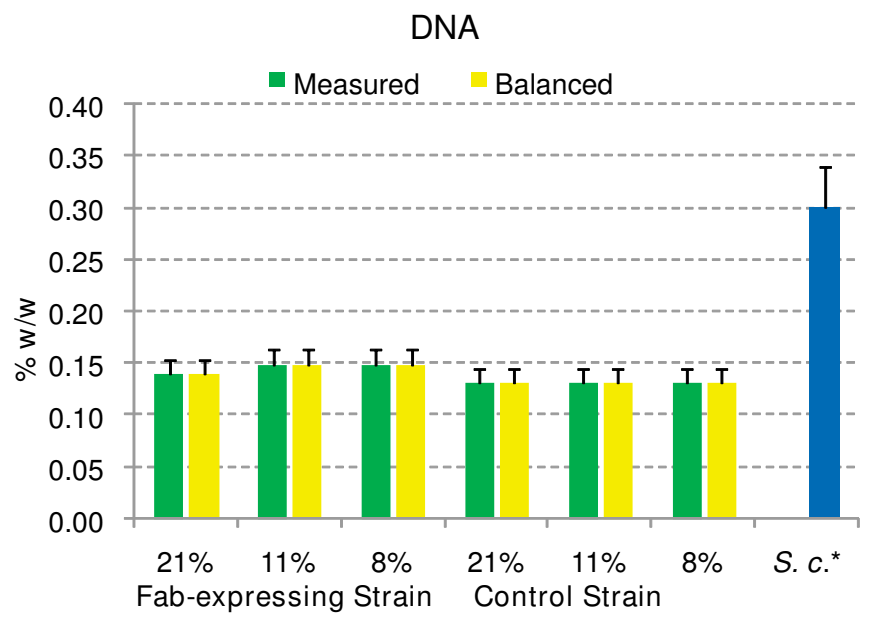

\section{Figure 2}

Summary of the macromolecular biomass composition results obtained for the different experimental conditions and the final reconciled value, Top left: Protein content, given as percentage of dry weight, measured using the Lowry method and calculated as the sum of extracted amino acids (A.a.), together with its reconciled value. Top right: Carbohydrate content \% dry weight together with its reconciled value. Bottom left: RNA content given as percentage of dry weight together with its reconciled value. Bottom right: DNA content given as percentage of dry weight together with its reconciled value. S.c.: S. cerevisiae. * Data from Lange and Heijnen 200 I [II] for S. cerevisiae in blue bars.

are required in order to assess the potential impact of Fab production on total protein content and amino acid composition.

\section{RNA content}

The results obtained for RNA content are shown in Figure 2 (bottom left). In this case, the control strain seemed to show a decrease in the RNA content as the oxygen availability was reduced, while in the Fab-expressing strain this effect was only apparent for the change from normoxic $\left(21 \% \mathrm{O}_{2}\right)$ to the lower oxygenation conditions whereas the RNA content in cells grown under oxygen limiting and hypoxic conditions remained similar.
Nevertheless, considering that RNA levels are expressed in relative terms (\% weight $\mathrm{RNA} / \%$ dry cell weight), these variations do not appear to be relevant when compared to the corresponding variations observed for the major cell components (e.g. cell protein). On the other hand, when comparing the control strain with the Fab-expressing strain at the same growth conditions, the RNA levels appeared to be generally slightly higher in the Fabexpressing strain. Nevertheless, such differences were not statistically significant for all oxygenation conditions. Notably, the relative decrease in RNA content under reduced oxygen availability conditions seemed to be less pronounced for the Fab-expressing strain. One might 


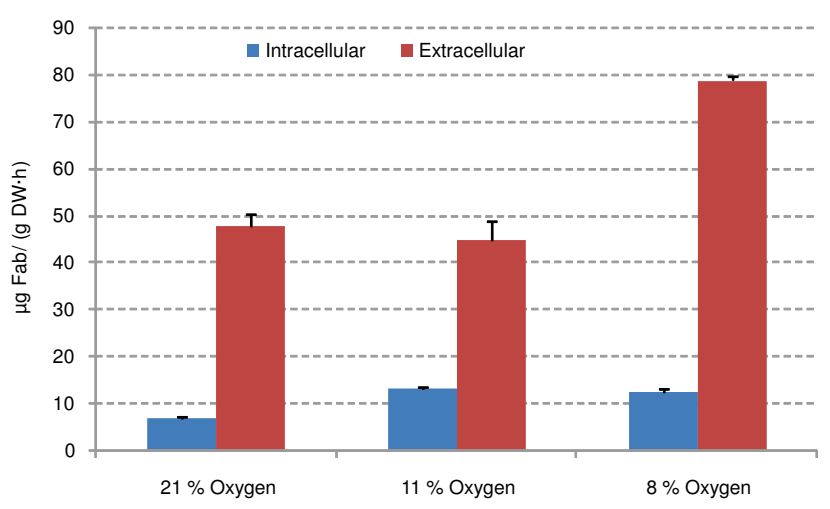

Figure 3

Effect of decreasing oxygen supply on Fab heterologous protein production. Measured Fab content in soluble cell extracts and in the extracellular medium of chemostat cultures of the Fab-producing strain growing under the different oxygenation conditions.

speculate that the increase in heterologous protein production under hypoxic conditions could result in higher RNA levels than in the control strain. Overall, the average value of all RNA levels measured for P. pastoris, appeared to be similar to those available from $S$. cerevisiae [11].

\section{Carbohydrate content}

Figure 2 (top right), shows the cell's total carbohydrate content measured for both strains grown under the three tested oxygenation conditions. The control strain seemed to present fairly constant carbohydrate levels under all oxygenation conditions, which as an average, were comparable to the $S$. cerevisiae levels [11]. However, the Fabexpressing strain showed a significant decrease in its relative carbohydrate content as the oxygen availability decreased. Notably, this decrease was coherent with the higher increase in the relative total protein content and the lower decrease in RNA content in the Fab-expressing strain than in the control strain as the oxygen availability was reduced.

Moreover, although the total carbohydrates content changed slightly, glycogen relative amounts were different depending on the oxygenation conditions, showing a significantly higher value in cells grown under normoxic conditions than in the oxygen-limited and hypoxic ones (Figure 4). These results could be explained by the need to secrete differently reduced carbon compounds to the media in limited-oxygen and hypoxic conditions to maintain the redox balance inside the cell (see Metabolite mass balance section) Interestingly, one of the glycogen synthases (Gsy1) from S. cerevisiae appears to be regulated by

Table I: Amino acid composition of the whole protein extract for all the conditions and strains tested

\begin{tabular}{|c|c|c|c|c|c|c|c|}
\hline \multirow{3}{*}{$\% \mathrm{~mol} / \mathrm{mol}$} & \multicolumn{6}{|c|}{ Pichia pastoris } & \multirow{3}{*}{ Saccharomyces cerevisiae * } \\
\hline & \multicolumn{3}{|c|}{ Fab-expressing Strain } & \multicolumn{3}{|c|}{ Control strain } & \\
\hline & $21 \%$ & $11 \%$ & $8 \%$ & $21 \%$ & $11 \%$ & $8 \%$ & \\
\hline Asx & 8.82 & 9.78 & 9.59 & 8.78 & 9.51 & 9.78 & 9.28 \\
\hline Thr & 5.88 & 5.98 & 5.78 & 5.77 & 5.90 & 6.16 & 5.57 \\
\hline Ser & 6.26 & 6.65 & 6.73 & 6.43 & 6.76 & 6.90 & 5.33 \\
\hline Glx & 17.81 & 16.24 & 15.64 & 18.55 & 16.19 & 14.33 & 15.48 \\
\hline Pro & 3.83 & 4.08 & 4.47 & 3.67 & 4.00 & 4.76 & 4.22 \\
\hline Gly & 6.86 & 7.34 & 7.42 & 7.12 & 7.28 & 7.53 & 8.89 \\
\hline Ala & 10.40 & 9.92 & 10.13 & 10.68 & 9.74 & 9.88 & 9.77 \\
\hline Val & 5.88 & 6.05 & 6.09 & 5.58 & 6.78 & 6.16 & 7.33 \\
\hline Cys & 0.15 & 0.15 & 0.14 & b.d. & 0.22 & 0.13 & 0.14 \\
\hline Met & 0.79 & 0.67 & 0.78 & 0.77 & 0.80 & 0.70 & 1.14 \\
\hline lle & 4.64 & 4.68 & 4.76 & 4.12 & 4.45 & 4.70 & 5.89 \\
\hline Leu & 6.96 & 7.26 & 7.46 & 6.99 & 7.23 & 7.94 & 8.01 \\
\hline Tyr & 2.16 & 2.22 & 2.27 & 2.13 & 2.21 & 2.47 & 1.96 \\
\hline Phe & 3.20 & 3.30 & 3.33 & 3.03 & 3.21 & 3.37 & 3.76 \\
\hline Orn & 1.04 & 1.02 & 0.86 & 1.53 & 1.21 & 0.93 & 0.24 \\
\hline Lys & 6.41 & 7.07 & 6.93 & 6.33 & 7.03 & 6.93 & 6.57 \\
\hline His & 1.89 & 1.87 & 1.87 & 1.79 & 1.78 & 1.89 & 1.93 \\
\hline Trp & 1.40 & 1.40 & 1.40 & 1.40 & 1.40 & 1.40 & 1.96 \\
\hline Arg & 7.04 & 5.72 & 5.76 & 6.74 & 5.68 & 5.45 & 3.86 \\
\hline
\end{tabular}

Amino acid composition measured for the different experimental conditions (\% $\mathrm{O}_{2}$ in the inlet gas: $\left.21,11,8\right)$ and for the different strains. Data given as percentage of each amino acid in the total pool of amino acids. * Data from Lange and Heijnen $200 \mathrm{I}$ [II] for S. cerevisiae. Glx represents the pair Glu/Gln. Asx represents the pair Asp/Asn. b.d: below detection limit. 
Table 2: Average amino acid composition of the whole protein extract between the two strains for the different experimental conditions tested

\begin{tabular}{|c|c|c|c|c|}
\hline \multirow[b]{2}{*}{$\begin{array}{c}\% \\
\mathrm{~mol} / \mathrm{mol}\end{array}$} & \multicolumn{3}{|c|}{ Pichia pastoris } & \multirow[t]{2}{*}{ Saccharomyces cerevisiae * } \\
\hline & $21 \%$ & $11 \%$ & $8 \%$ & \\
\hline Asx & 8.67 & 9.50 & 9.55 & 9.28 \\
\hline Thr & 5.74 & 5.85 & 5.88 & 5.57 \\
\hline Ser & 6.25 & 6.61 & 6.72 & 5.33 \\
\hline Glx & 17.91 & 15.98 & 14.76 & 15.48 \\
\hline Pro & 3.69 & 3.98 & 4.55 & 4.22 \\
\hline Gly & 6.89 & 7.21 & 7.36 & 8.89 \\
\hline Ala & 10.39 & 9.69 & 9.86 & 9.77 \\
\hline Val & 5.65 & 6.32 & 6.03 & 7.33 \\
\hline Cys & 0.15 & 0.18 & 0.13 & 0.14 \\
\hline Met & 0.76 & 0.73 & 0.73 & 1.14 \\
\hline Ile & 4.32 & 4.50 & 4.66 & 5.89 \\
\hline Leu & 6.87 & 7.14 & 7.59 & 8.01 \\
\hline Tyr & 2.11 & 2.18 & 2.33 & 1.96 \\
\hline Phe & 3.07 & 3.21 & 3.30 & 3.76 \\
\hline Orn & 1.27 & 1.10 & 0.88 & 0.24 \\
\hline Lys & 6.28 & 6.94 & 6.83 & 6.57 \\
\hline $\mathrm{His}$ & 1.81 & 1.80 & 1.86 & 1.93 \\
\hline Trp & 1.38 & 1.38 & 1.38 & 1.96 \\
\hline Arg & 6.79 & 5.62 & 5.52 & 3.86 \\
\hline
\end{tabular}

Amino acid composition measured for the different experimental conditions $\left(\% \mathrm{O}_{2}\right.$ in the inlet gas: $\left.2 \mathrm{I}, \mathrm{II}, 8\right)$. Data given as percentage of each amino acid in the total pool of amino acids. * Data from Lange and Heijnen $200 \mathrm{I}$ [II] for S. cerevisiae. Glx represents the pair Glu/

Gln. Asx represents the pair Asp/Asn.

Rox1, a transcriptional factor that regulates responses to oxygen [19], so one could speculate that glycogen metabolism in $P$. pastoris is also regulated at the level of gene expression by an environmental stressor such as hypoxia. On the other hand, the trehalose values did not show any clear tendency when varying the oxygenation degree or the strain genetic background.

\section{DNA content}

As shown in Figure 2 (bottom right), the measured DNA content of $P$. pastoris was lower than the amounts previously reported for $S$. cerevisiae [11]. This might partially reflect the smaller size of the $P$. pastoris genome (haploid set of 4 chromosomes resulting in $9.43 \mathrm{Mbp}$ [17]) compared to the one of $S$. cerevisiae (haploid set of 16 chromosomes resulting in $12 \mathrm{Mbp}$ [20]). On the other hand, industrial strains of $S$. cerevisiae are usually found under diploid (or even polyploid) state [21], while P. pastoris is in haploid state [22]. Combination of both factors could explain the differences among the measured DNA content of the two species.

\section{Lipid content}

With respect to the lipid fraction content, an effort was done to quatify the total lipid content of the biomass as well as determining semi-quantatively the major compo-

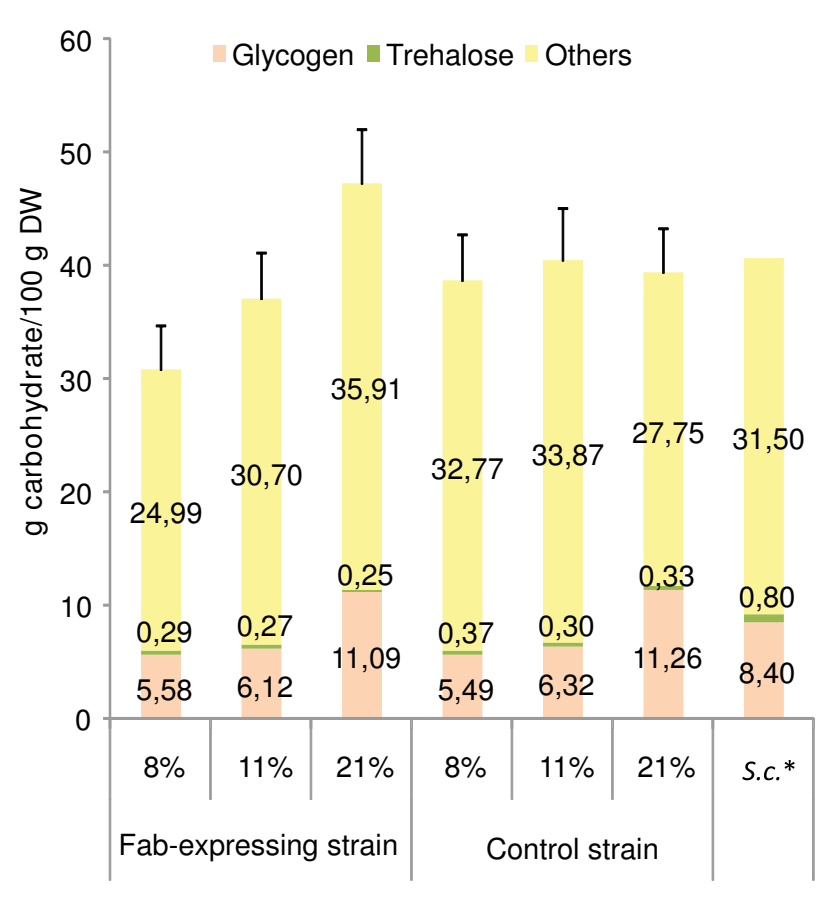

Figure 4

Principal carbohydrates. Total carbohydrate, glycogen and trehalose amounts measured for each strain and oxygenation condition. * Data from Forster et al. 2003 [3] for S. cerevisiae.

nents of this fraction. However, the methodology employed showed low levels of total lipid recovery. Therefore, the data obtained was only used to determine the major components of the lipid family, whereas the total amount was instead estimated during the reconciliation procedure (see below). The total lipid content of the biomass calculated by the reconciliation procedure appeared to be close to the data available for S. cerevisiae [11].

On the other hand, the major lipid components identified in the thin layer chromatography were triacylglycerides (TAG), ergosterol (ERG), phosphatidylcholine (PC), and phosphatidylethanolamine (PE) in order of abundance. The triacylglycerides relative amounts seemed to increase when the oxygen availability decreased while ergosterol seemed to decrease. Nevertheless, the technique used for this analysis did not allow for a very precise quantification of each lipid component. Therefore, the average percentage of abundance, for each of the major lipid components, was taken to calculate the lipid C-mol formula: triacylglycerides $(57.2 \% \mathrm{w} / \mathrm{w})$, ergosterol and ergosterol esters $(26.8 \% \mathrm{w} / \mathrm{w})$, phosphatidylcholine $(10.0 \% \mathrm{w} / \mathrm{w})$, phosphatidylethanolamine $(5.2 \% \mathrm{w} / \mathrm{w})$, phosphatidylinositol + phosphatidylserine $(0.4 \% \mathrm{w} / \mathrm{w})$, cardiolipin $(0.3 \% \mathrm{w} / \mathrm{w})$ and phosphatidic acid $(0.1 \% \mathrm{w} / \mathrm{w})$. 


\section{Elemental biomass composition}

As explained above, besides the macromolecular composition of the biomass, its content of major chemical elements can be also considered. Usually, the elements that are taken into account are those that add up to nearly $90 \%$ of the dry weight, namely $\mathrm{C}, \mathrm{H}, \mathrm{O}, \mathrm{N}, \mathrm{P}$, and $\mathrm{S}$. In this study, only C, H, N, S and ash content were measured (see Additional file 1). For the reconciliation procedure, $\mathrm{P}$ was included into a composite compound which also included ashes. Therefore, the reconciliation procedure calculated the oxygen content that fulfilled the global balance taking into account all the available information (see below: Reconciled biomass composition).

\section{Consistency check and data reconciliation}

As mentioned in the Introduction section, in order to perform detailed metabolic flux analyses calculations, it is necessary to verify the consistency of the data obtained and, when different kinds of complementary or redundant data is available, to obtain the best estimation of the studied system using common data reconciliation techniques [23]. This procedure was performed in two steps. In the first one, the different biomass compositional data available was used to obtain a reconciled biomass composition. In the second step, the consistency check of the measured substrate consumption together with the biomass and products generated was performed.

\section{Reconciled biomass composition}

Calculation of a reconciled biomass composition from the biomass compositional data described above was performed using the maximum likelihood method as described by Lange and Heijnen [11]. In short, the method allows the calculation of the best estimation of the biomass composition by solving a linear system which takes conservation laws of elemental and mass balances into account. The obtained experimental data is considered using a weight proportional to the confidence of the analysis.

For the reconciliation procedure, the elemental composition of the macromolecular compounds, in terms of a Cmol formula, of each biomass component was calculated as follows: Protein elemental composition was calculated from the measured relative abundance of each amino acid in $P$. pastoris samples. The elemental composition of the carbohydrate component was considered to be a glucose polymer. The elemental composition of lipids was calculated as an average of the major compounds identified. DNA elemental composition was calculated from the percentage of its nucleotide content in $P$. pastoris [17]. RNA elemental composition was calculated as proposed by Stephanopoulos [13]. Other components, such as metals, $\mathrm{H}_{2} \mathrm{O}$ and sulphate were included in an identical way as described for S. cerevisiae in Lange and Heijnen [11] (See Additional file 2 for the C-mol formulas).

Table 3 shows the values for the biomass composition obtained after the reconciliation procedure was applied. The reconciliation procedure provides the best estimation of the biomass composition, including the lipid content or the oxygen values that were not measured. The biomass composition obtained this way is also consistent from the viewpoint that all the macromolecular elements considered add to $100 \%$ and the chemical elements composing them also add up to $100 \%$. Moreover, the standard deviation of the estimated values is given, as is of utmost importance for any further numerical treatment. Overall, the calculated biomass compositional values show that, as the oxygen availability is decreased, there is a slight increase in the protein content of the biomass. Also, the calculated data indicates an increase in the total lipid content, which has a higher degree of reduction than the proteins or the carbohydrates. Nevertheless, taking into consideration the standard deviation calculated for the lipids, the confidence for the calculated values is low and, therefore, more data will have to be obtained in the future to confirm the indicated tendency.

The reconciliation procedure also calculates the major chemical elements contained in the biomass, including the non measured oxygen. This allows calculating a biomass carbon elemental formula, shown in Table 4. It can be observed that the ratio $\mathrm{H}: \mathrm{O}$ and the biomass degree of reduction increase as the oxygen availability is decreased. This is in agreement with the accumulation of more reduced biomass components, for instance, an increase in lipid content. This effect is apparently more pronounced in the Fab-producing strain. The resulting reconciled biomass composition was used in the rest of the calculations.

\section{Metabolite mass balances}

One of the key points in any fermentation study is to validate the measured consumption of substrates and generation of products. This step has been performed following the well established statistical procedures for the purpose $[12,13,24-27]$, which are similar to the one already followed for the reconciliation of the biomass composition data. The biomass C-molecular formula calculated in the previous step is used in this procedure. Then, the $\chi^{2}$-distributed consistency index $h$ has been calculated for the reconciled data to test for the presence of gross errors according to a well established procedure (Wang [23], van der Heijden [25-27] and Stephanopoulos [13]).

In a first approximation, it was considered that biomass and $\mathrm{CO}_{2}$ generation under normoxic conditions resulted from the glucose and oxygen consumption, while reduc- 
Table 3: Biomass composition calculated after the reconciliation procedure

\begin{tabular}{|c|c|c|c|c|c|c|c|c|c|c|c|c|}
\hline & \multicolumn{6}{|c|}{ Fabb-expressing strain } & \multicolumn{6}{|c|}{ Control strain } \\
\hline & $21 \%$ & & $11 \%$ & & $8 \%$ & & $21 \%$ & & $11 \%$ & & $8 \%$ & \\
\hline & $\% w / w$ & sd & $\% w / w$ & sd & $\% w / w$ & sd & $\% w / w$ & sd & $\% w / w$ & sd & $\% w / w$ & sd \\
\hline Protein & 34.9 & 2.3 & 37.0 & 2.4 & 40.0 & 2.6 & 37.0 & 2.4 & 37.8 & 2.5 & 38.9 & 2.6 \\
\hline Carbohydrate & 41.7 & 4.0 & 35.0 & 3.3 & 30.1 & 2.9 & 36.9 & 3.5 & 39.7 & 4.0 & 35.6 & 3.5 \\
\hline Lipid & 6.6 & 3.4 & 9.8 & 3.2 & 10.3 & 3.2 & 6.2 & 3.3 & 7.8 & 3.5 & 8.7 & 3.3 \\
\hline RNA & 6.9 & 0.7 & 6.2 & 0.6 & 6.1 & 0.6 & 6.6 & 0.7 & 6.0 & 0.6 & 4.9 & 0.5 \\
\hline DNA & 0.14 & 0.01 & 0.15 & 0.01 & 0.15 & 0.01 & 0.13 & 0.01 & 0.13 & 0.01 & 0.13 & 0.01 \\
\hline $\mathrm{SO}_{4}$ & 0.2 & 0.2 & 0.2 & 0.2 & 0.1 & 0.2 & 0.3 & 0.3 & 2.7 & 3.5 & 0.2 & 0.2 \\
\hline $\mathrm{H}_{2} \mathrm{O}$ & 3.2 & 2.5 & 5.2 & 2.4 & 6.8 & 2.2 & 6.3 & 2.4 & 0.2 & 0.2 & 5.0 & 2.4 \\
\hline Metals & 6.4 & 0.4 & 6.4 & 0.4 & 6.4 & 0.4 & 6.4 & 0.4 & 5.6 & 1.2 & 6.5 & 0.4 \\
\hline C & 44.3 & 1.4 & 44.6 & 1.4 & 44.4 & 1.4 & 43.0 & 1.4 & 45.6 & 1.2 & 44.7 & 1.4 \\
\hline $\mathrm{H}$ & 6.2 & 0.2 & 6.5 & 0.2 & 6.6 & 0.2 & 6.3 & 0.2 & 6.0 & 0.2 & 6.4 & 0.2 \\
\hline $\mathrm{N}$ & 6.7 & 0.4 & 6.9 & 0.4 & 7.4 & 0.4 & 6.9 & 0.4 & 7.0 & 0.4 & 7.0 & 0.4 \\
\hline 0 & 35.6 & 1.4 & 34.8 & 1.4 & 34.3 & 1.4 & 36.4 & 1.4 & 34.1 & 1.3 & 34.6 & 1.4 \\
\hline$S$ & 0.2 & 0.1 & 0.2 & 0.1 & 0.1 & 0.1 & 0.2 & 0.1 & 0.2 & 0.1 & 0.2 & 0.1 \\
\hline Ashes & 7.1 & 0.4 & 7.1 & 0.4 & 7.2 & 0.4 & 7.1 & 0.4 & 7.1 & 0.4 & 7.1 & 0.4 \\
\hline
\end{tabular}

Biomass composition in terms of macromolecular and elemental compounds for the different experimental conditions $\left(\% \mathrm{O}_{2}\right.$ in the inlet air $2 \mathrm{I}, \mathrm{II}$, 8).

tion in the oxygen availability resulted in the generation some by-products such as pyruvate, glycerol, ethanol and citrate. As can be observed in Table 5, a carbon balance performed in both strains for the normoxic conditions ( $21 \%$ of oxygen in the inlet air), indicated that most of the carbon was taken into account, as there was only a mismatch of $6 \%$ and $1 \%$ respectively, well in agreement with the precision of the analyses. However, in the case of cultivations under oxygen-limiting and hypoxic conditions, the carbon balance showed a significant mismatch, sug- gesting that a compound was most probably missing. In addition, observation of the HPLC chromatograms of cleared supernatants from these cultivations (Additional file 3) showed an unidentified peak which increased as oxygen limitation was more severe. The compound corresponding to this peak was isolated and further analysed by LC-MS, resulting in the identification of a compound of a molecular mass of 197 which taking into account the effect of the reacting eluent (formic acid, $46 \mathrm{~m} / \mathrm{z}$ ) results in a metabolite of $151 \mathrm{~g} / \mathrm{mol}$.

Table 4: Biomass C-molecular formula calculated after the reconciliation procedure

\begin{tabular}{|c|c|c|c|c|c|}
\hline & & mass formula & $\mathbf{C : N}$ & H:O & $(\gamma)$ \\
\hline \multirow{3}{*}{$\begin{array}{c}\text { Fab } \\
\text { Expressing } \\
\text { Strain }\end{array}$} & $21 \%$ oxygen & $\mathrm{CH}_{1.665} \mathrm{~N}_{0.134} \mathrm{O}_{0.602} \mathrm{~S}_{0.0039}$ & 7.45 & 2.77 & 4.11 \\
\hline & II\% oxygen & $\mathrm{CH}_{1.731} \mathrm{~N}_{0.137} \mathrm{O}_{0.585} \mathrm{~S}_{0.0015}$ & 7.30 & 2.96 & 4.18 \\
\hline & $8 \%$ oxygen & $\mathrm{CH}_{1.775} \mathrm{~N}_{0.144} \mathrm{O}_{0.579} \mathrm{~S}_{0.0012}$ & 6.94 & 3.06 & 4.20 \\
\hline \multirow{3}{*}{$\begin{array}{l}\text { Control } \\
\text { Strain }\end{array}$} & $21 \%$ oxygen & $\mathrm{CH}_{1.761} \mathrm{~N}_{0.143} \mathrm{O}_{0.636} \mathrm{~S}_{0.0018}$ & 7.02 & 2.77 & 4.09 \\
\hline & II\% oxygen & $\mathrm{CH}_{1.585} \mathrm{~N}_{0.135} \mathrm{O}_{0.560} \mathrm{~S}_{0.0016}$ & 7.39 & 2.83 & 4.08 \\
\hline & $8 \%$ oxygen & $\mathrm{CH}_{1.726} \mathrm{~N}_{0.138} \mathrm{O}_{0.581} \mathrm{~S}_{0.0014}$ & 7.26 & 2.97 & 4.17 \\
\hline \multicolumn{2}{|c|}{ S. cerevisiae * } & $\mathrm{CH}_{1.748} \mathrm{~N}_{0.148} \mathrm{O}_{0.596} \mathrm{~S}_{0.0018}$ & 6.76 & 2.93 & 4.22 \\
\hline
\end{tabular}

Elementary composition of biomas, expressed as $\mathrm{C}$-molecular formula, for the different strains and experimental conditions $\left(\% \mathrm{O}_{2}\right.$ in the inlet air: $2 \mathrm{I}, \mathrm{II}, 8)$. C:N carbon:nitrogen ratio; $\mathrm{H}: \mathrm{O}$ hydrogen:oxygen ratio. $\gamma$ : reduction degree of the biomass. * Data from Lange and Heijnen $200 \mathrm{I}[\mathrm{II}]$ for S. cerevisiae. 
Table 5: Measured substrates and products consumed/produced at steady state in each experimental condition

\begin{tabular}{|c|c|c|c|c|c|c|c|c|c|c|c|c|}
\hline \multirow{3}{*}{$\mathrm{mmol} / \mathrm{gDW} \cdot \mathrm{h}$} & \multicolumn{6}{|c|}{ Fab-expressing strain } & \multicolumn{6}{|c|}{ Control strain } \\
\hline & \multicolumn{2}{|c|}{$21 \%$} & \multicolumn{2}{|c|}{$11 \%$} & \multicolumn{2}{|c|}{$8 \%$} & \multicolumn{2}{|c|}{$21 \%$} & \multicolumn{2}{|c|}{$11 \%$} & \multicolumn{2}{|c|}{$8 \%$} \\
\hline & & sd & & sd & & sd & & sd & & sd & & sd \\
\hline Glucose & -0.99 & 0.05 & -1.33 & 0.07 & -1.74 & 0.09 & -0.99 & 0.05 & -1.32 & 0.07 & -1.92 & 0.10 \\
\hline OUR & -2.12 & 0.17 & -1.57 & 0.08 & -0.54 & 0.10 & -2.12 & 0.17 & -1.66 & 0.33 & -0.28 & 0.01 \\
\hline CER & 2.37 & 0.19 & 2.03 & 0.10 & 1.65 & 0.08 & 2.37 & 0.19 & 2.09 & 0.42 & 1.35 & 0.27 \\
\hline Biomass & 3.01 & 0.30 & 3.71 & 0.37 & 3.73 & 0.19 & 3.59 & 0.36 & 3.70 & 0.37 & 3.76 & 0.38 \\
\hline Ethanol & - & - & 0.33 & 0.02 & 1.00 & 0.05 & - & - & 0.31 & 0.02 & 1.16 & 0.06 \\
\hline Glycerol & - & - & 0.01 & 0.001 & 0.02 & 0.001 & - & - & 0.02 & 0.001 & 0.02 & 0.001 \\
\hline Citrate & 0.03 & 0.002 & 0.02 & 0.001 & 0.04 & 0.002 & 0.01 & 0.001 & 0.02 & 0.001 & 0.05 & 0.02 \\
\hline Arabinitol & - & - & 0.21 & 0.01 & 0.42 & 0.02 & - & - & 0.10 & 0.01 & 0.40 & 0.13 \\
\hline Pyruvate & - & - & 0.06 & 0.003 & 0.09 & 0.005 & - & - & 0.06 & 0.002 & 0.12 & 0.01 \\
\hline \% C Balance Error excluding arabinitol & $6.4 \%$ & & $15.7 \%$ & & $23.9 \%$ & & $1.3 \%$ & & $14.5 \%$ & & $29.3 \%$ & \\
\hline \% C Balance Error including arabinitol & $6.4 \%$ & & $2.5 \%$ & & $3.7 \%$ & & $1.3 \%$ & & $8.2 \%$ & & $11.9 \%$ & \\
\hline
\end{tabular}

Substrate consumption, biomass and metabolites production rates, for each strain and the different experimental conditions $\left(\% \mathrm{O}_{2}\right.$ in the inlet air: $2 \mathrm{I}, \mathrm{II}, 8)$. Bottom rows: values of the carbon balance mismatch in percentage including or excluding arabinitol. OUR, oxygen uptake rate; CER, $\mathrm{CO}_{2}$ exchange rate.

\section{Identification of the unknown extracellular metabolite}

To identify the unknown extracellular compound, a hypoxic culture under steady state conditions was fed with fresh medium containing a carbon source mixture consisting of $12 \%(\mathrm{w} / \mathrm{w})$ of uniformly ${ }^{13} \mathrm{C}$-labeled glucose and $88 \%(\mathrm{w} / \mathrm{w})$ of unlabeled glucose, as described in the materials and methods section. Filtered samples of output culture media were submitted to an NMR analysis in order to identify the unknown compound. The NMR results (Additional file 1) were compared with the ${ }^{13} \mathrm{C}-\mathrm{NMR}$ Japanese database spectra SBDS (Spectral Database for Organic Compounds, http://riodb01.ibase.aist.go.jp/

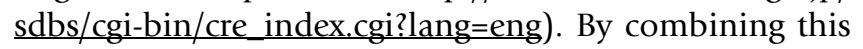
information with the molecular weight determined by LCMS and its retention time in HPLC analysis (Additional file 3), the unknown metabolite was identified as arabinitol (MW 152).

Arabinitol, a C5 sugar alcohol related to the pentose phosphate pathway, has been previously shown to be produced by a variety of yeast species during fermentation. For instance, glycerol and arabinitol accumulation has been previously observed in Pichia anomala cultures during growth in high-salt environments and on highly concentrated sugar substrates by Bellinger and Larher [28] and Tokuoka et al. [29]. Passoth and collaborators [30] suggested that arabinitol has the same physiological role as glycerol in the protection to osmotic stress, since they also found a glycerol and arabinitol accumulation under oxygen limiting conditions in P. anomala.

In yeast ( $S$. cerevisiae), glycerol is produced under oxygen limitation to reoxidize the redox equivalents produced during amino acid synthesis [31]. Arabinitol has not yet been reported to be involved in the redox metabolism during fermentative growth; however, it is possible that arabinitol formation also plays a role in the redox balance of the cells [30].

Once the missing compound was identified, it was quantified by HPLC. Including the arabinitol in the mass balance allowed to significantly improve the carbon balance and the percentage of carbon recovery reached values similar to the ones obtained for the cultivations under normoxic conditions. With this additional analysis, a reconciliation step including all available data was performed resulting in improved consistency index values (h values). Figure 5 shows the measured values, as well as the reconciled values for the involved metabolites in terms of $\mathrm{mmol} /(\mathrm{gDW} \cdot \mathrm{h})$. As expected, it can be observed that the oxygen consumed per unit of dry weight (DW) decreased when oxygen limitation and hypoxic conditions were applied. Also, the amount of glucose consumed per unit of dry weight is increased. This increased specific consumption of carbon source results mainly in the production of the above mentioned metabolites as a result of the imposed oxygen limitation conditions.

\section{Conclusions}

In this study, different experimental methods were applied in order to obtain first hand data on the biomass composition of $P$. pastoris. The diversity of the data obtained was combined, using ad hoc data reconciliation techniques, and the best estimation of the biomass composition was obtained. 

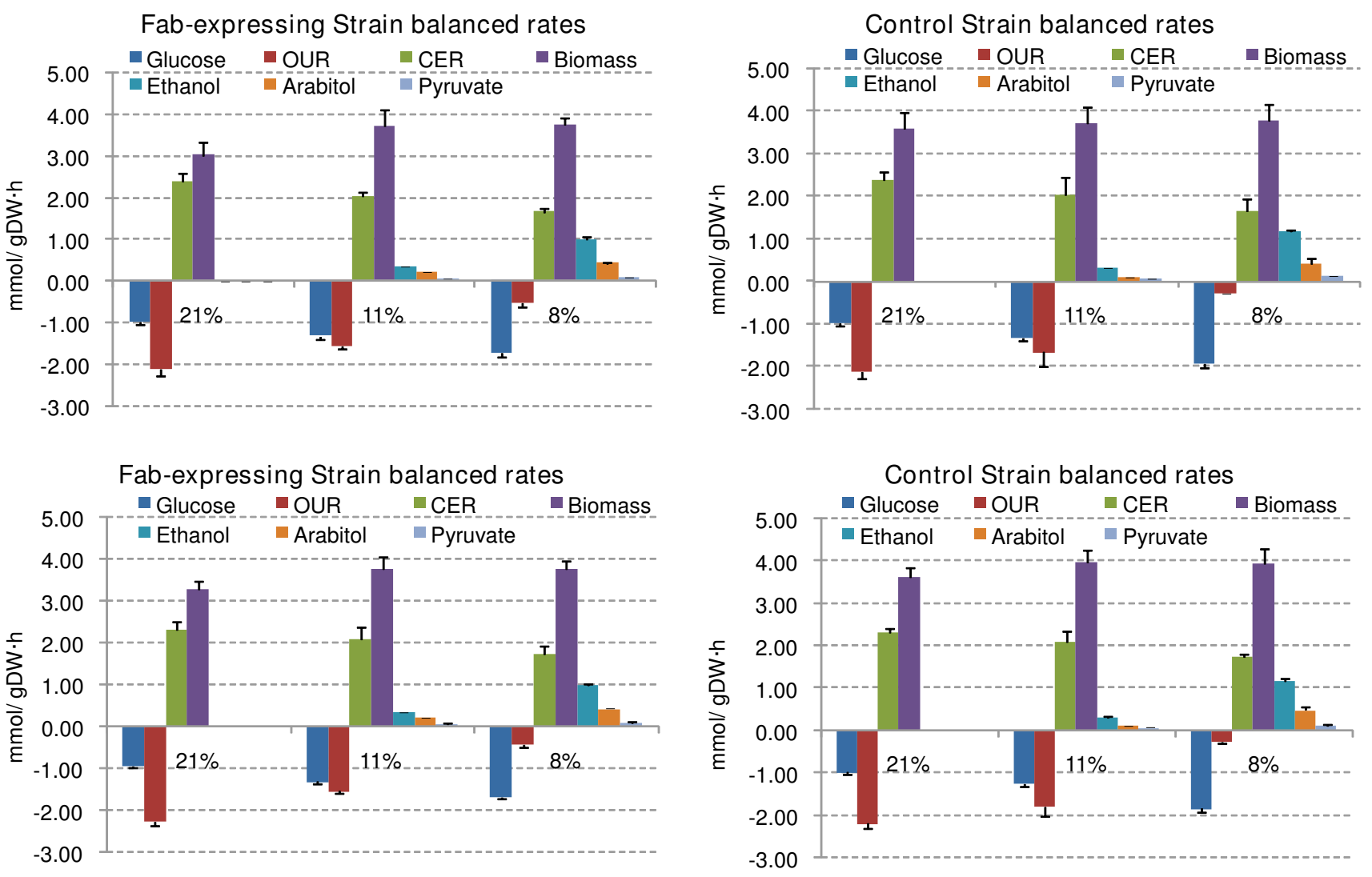

\section{Figure 5}

Substrates consumed and metabolites generated for the different experimental conditions. Top row: measured values for the Fab-expressing strain (left) and for the control strain (right). Bottom row reconciled values for the Fab-expressing strain (left) and for the control strain (right). Negative values represent substrate consumed, while positive values represent products generated. OUR, oxygen uptake rate; $\mathrm{CER}, \mathrm{CO}_{2}$ exchange rate.

Application of the elemental mass balances to the input output metabolite data allowed detecting the lack of one major metabolite. Using complementary NMR data the missing metabolite was identified as being arabinitol. Quantification of this metabolite and its incorporation into the metabolite mass balances allowed to validate the obtained data and to calculate reconciled and consistent fermentation data. The obtained results will be used in metabolic flux analyses of $P$. pastoris, which are being carried out in parallel with transcriptomics and proteomics analyses, in a baseline study aimed at the understanding of the effect of the oxygenation conditions on heterologous protein production in $P$. pastoris .

\section{Methods}

\section{Strains}

In this study, two different strains were used: A $P$. pastoris $\mathrm{X}$-33 (wild type phenotype, Invitrogen) transformed with pGAPa A (Invitrogen) as mock vector (control strain), and a X-33-derived strain expressing the human antibody fragment (Fab) 3H6 fragment under the transcriptional control of glyceraldehyde-3-phosphate dehydrogenase (GAP) constitutive promoter, using the secretion signal sequence from the $S$. cerevisiae a mating factor (Fabexpressing strain) [14].

\section{Cultivation conditions}

Chemostat cultivations were performed in a 2-liter benchtop bioreactor (B. Braun Biotech International, Biostat B), as previously described [16]. Briefly, cells were grown under carbon-limited conditions at a dilution rate $(D)$ of $0.1 \mathrm{~h}^{-1}$, with different oxygen concentrations in the bioreactor inlet air. The total inlet gas flow was controlled by mass flow meters (Bronkhorst High-Tech) at $1.5 \mathrm{vvm}$. The outlet gas flow was dried through two silica gel columns to remove the humidity and analyzed to determine its $\mathrm{CO}_{2}$ and $\mathrm{O}_{2}$ content (BCP- $\mathrm{CO}_{2}$ and $\mathrm{BCP}-\mathrm{O}_{2}$ Sensors, BlueSens). In the cultures that received less than $21 \%$ of $\mathrm{O}_{2}$ in 
the inlet gas stream (that is, $11 \%$ and $8 \%$ of $\mathrm{O}_{2}$ ), air was mixed with the necessary volume of $\mathrm{N}_{2}$ so that the total gas flow of $1.5 \mathrm{vvm}$ was maintained constant. The pressure in the culture vessel was maintained at 1.2 bars using a pressure valve (GO Inc). The $\mathrm{pH}$, stirring speed and temperature were maintained at 5 (with $20 \% \mathrm{NH}_{3}$ ), $700 \mathrm{rpm}$ and $25^{\circ} \mathrm{C}$, respectively.

During the experiments the data acquisition and control of the different variables was done using UAB proprietary software (O. Cos, Universitat Autònoma de Barcelona). For each independent experiment, chemostat culture conditions were maintained constant for at least 5 residence times to allow reaching a metabolic steady state, except for the hypoxic conditions $\left(8 \% \mathrm{O}_{2}\right.$ in the inlet air), where a wash out after 3.5 residence times had previously been observed [16]. In this case, samples were taken just after 3 residence times and analyzed for biomass composition. At least three independent samples, from two independent cultivations, were analyzed for each tested condition.

\section{Biomass Analyses}

Determination of biomass ash content

Culture samples of $20 \mathrm{ml}$ volume were centrifuged at $5,000 \mathrm{rpm}, 4^{\circ} \mathrm{C}$ for $5 \mathrm{~min}$ and the pellets were washed twice in $20 \mathrm{ml}$ of $20 \mathrm{mM}$ Tris $\mathrm{HCl}, \mathrm{pH}$ 7.6. The resuspended cells were filtered through pre-dried glass fibre filters (Millipore) and dried overnight at $100^{\circ} \mathrm{C}$. Combustion of the pre-dried biomass was done by placing the glass fibre filters in ceramic cups (Millipore) in an oven (Hengstler) at $550^{\circ} \mathrm{C}$ for $12 \mathrm{~h}$.

\section{Biomass lyophilisation}

Most of the analyses were performed using lyophilized biomass samples. To lyophilize the biomass a sample of cultivation broth was centrifuged at 13,000 rpm for $1 \mathrm{~min}$ and the cell pellet was washed twice with $1 \mathrm{ml}$ of $20 \mathrm{mM}$ Tris $\mathrm{HCl}, \mathrm{pH} 7.6$ to get a pellet free of culture medium. The recovered pellet was immediately frozen by immersion in an acetone-dry ice mixture followed by the lyophilization step under vacuum (Virtys Sentry).

\section{Biomass elemental analysis}

The elemental composition of the biomass was determined taking $1 \mathrm{mg}$ of a lyophilized biomass, adding $1 \mathrm{mg}$ of $\mathrm{V}_{2} \mathrm{O}_{5}$ and introducing the samples in an oven at $1000^{\circ} \mathrm{C}$. The volatile compounds were measured with an Elemental Analyzer (NA2100 ThermoFisher).

\section{Biomass amino acid composition}

Samples of $40 \mathrm{mg}$ of lyophilized biomass were hydrolyzed with $3 \mathrm{ml} 6 \mathrm{M} \mathrm{HCl}$ at $105^{\circ} \mathrm{C}$ for $24 \mathrm{~h}$. A $\mathrm{N}_{2}$ stream was used to remove the $\mathrm{O}_{2}$, minimizing the oxidation during hydrolysis. Following the hydrolyzation step, the volume of the samples was completed up to $50 \mathrm{ml}$ with deionised water (MilliQ). A volume of $500 \mu \mathrm{l}$ of the diluted samples and $100 \mu \mathrm{l}$ of $2500 \mu \mathrm{M}$ nor-leucin (nonproteinogenic amino acid used as internal standard), were mixed before being evaporated to dryness. The resulting pellets were dissolved with $1 \mathrm{ml}$ buffer solution (lithiumcitrate loading buffer $\mathrm{pH}$ 2.2, Biochrom) and filtered by ultracentrifugation using 10,000 Da cut-off filter (Microcon YM10, Millipore). A $50 \mu$ l volume of the filtrate was injected in an amino acid analyzer (Biochrom 30; using the Biochrom EZ Chrom software, for quantification) using a cation exchange chromatography column and post derivatisation with ninhidrine, (as described by Moore, Spackman, and Stein [32]). For the amino acid identification, the eluent (lithium citrate buffer, Biochrom UK) was heated up to $135^{\circ} \mathrm{C}$ and mixed with ninhydrine. Identification was done according to the known retention time of the amino acid standards in this conditions and quantification performed according to the previously performed calibration curves relating peak area with concentration (detection limit: $1 \mathrm{nmol}$, reproducibility: $1.5 \%$ for $10 \mathrm{nmol})$.

\section{Biomass total protein content}

Total protein content was determined by means of the Lowry method as described in [33] from a solution of lyophilized biomass at $0.5 \mathrm{~g} / \mathrm{l}$ dry weight. Protein concentration was calculated using bobine serum albumin (BSA) as standard.

\section{Biomass total carbohydrates content}

Total carbohydrates were determined by the phenol method as described in [33]. A $1 \mathrm{ml}$ sample of lyophilized biomass $(0.1 \mathrm{mg}$ dry biomass $/ \mathrm{ml})$ was mixed with $1 \mathrm{ml}$ phenol $5 \%$ and $5 \mathrm{ml} 96 \%$ sulphuric acid. After $10 \mathrm{~min}$ tubes were cooled $\left(15 \min 25^{\circ} \mathrm{C}\right)$. Absorbance at $488 \mathrm{~nm}$ was measured using glucose solutions as standard. Results were corrected for the presence of nucleic acid pentoses using a relative absorbance of $0.455 \mathrm{AU}$ and $0.264 \mathrm{AU}$ for RNA and DNA, respectively [11].

\section{Biomass glycogen content}

The glycogen content was analyzed as described in the literature [34]. Glycogen was hydrolyzed adding $10 \mathrm{ml}$ of $0.6 \mathrm{M} \mathrm{HCl}$ to $20 \mathrm{mg}$ of freeze dried biomass and incubating in a water bath at $100^{\circ} \mathrm{C}$ for $1 \mathrm{~h}$. After cooling, samples were filtered through $0.22 \mu \mathrm{m}$ filter (Millipore). The glucose produced was quantified using an automatic glucose analyzer (YSI 1500, Yellow Springs Instruments).

\section{Biomass trehalose content}

Determination of trehalose content of the biomass was performed according to [35].

$10 \mathrm{mg}$ of lyophilized biomass was resuspended in $5 \mathrm{ml}$ water and incubated for 15 minutes in a water bath. After 
cooling and centrifugation the cellular extract was rinsed twice with water and resuspended in $0.1 \mathrm{M}$ acetate buffer $\mathrm{pH}$ 4.5. A sample of $800 \mu \mathrm{l}$ of the washed cellular extract was mixed with $200 \mu \mathrm{l}$ of a threhalase (Sigma) solution $(1.37 \mu \mathrm{U} / \mu \mathrm{l}$ in acetate buffer $\mathrm{pH} 4.5)$ and incubated overnight. The glucose released was determined using a glucose oxidase kit (Sigma) using the same reaction mixture without threhalase as a blank.

\section{Biomass lipid content}

Lipid extraction was performed according to [36]. Briefly, $150 \mathrm{mg}$ of freeze dried biomass were extracted with hexane:isopropanol (3:2 v:v) overnight. After adding $0.47 \mathrm{M}$ $\mathrm{Na}_{2} \mathrm{SO}_{4}$ phases were separated with the aid of a centrifugation step. The hexane phase was recovered and evaporated to dryness under a $\mathrm{N}_{2}$ flow. The increase in dry weight of the tube was taken as total lipids. Pellet was redissolved in chloroform and further analyzed by thin layer chromatography using silica gel plates (Merck) and a mobile phase of chloroform:methanol:water:acetic acid (345:133:21:3). A standard was analyzed in parallel containing phosphatidic acid (Sigma), phosphatidyl serine (bovine, Fluka), phosphatidyl glycerol (bovine, Sigma), cardiolipine (bovine, sigma), phosphatidyl ethanolamine (bovine, sigma), phosphatidil inositol (bovine, sigma), phosphatidyl coline (bovine, sigma), ergosterol (Fluka) and triacilglycerides (Sigma) using a range of concentrations from 1 to $8 \mu \mathrm{g}$ of each standard. After running the chromatography the plates were stained either with iodine or with Sudan Black (Sebia). The developed images were quantified using an image analysis software (Multi gauge, Fujifilm) comparing the intensity of the stains with the standards.

\section{Biomass DNA content}

DNA content of biomass was determined by means of the Hoechst fluorescent dye method as described in [37]. In short, lyophilized biomass samples were dissolved in TNE buffer ( $1 \mathrm{M} \mathrm{NaCl}, 10 \mathrm{mM}$ EDTA, $0.1 \mathrm{M}$ Tris $\cdot \mathrm{HCl}, \mathrm{pH} 7.4)$ at a concentration of $25 \mathrm{mg} / \mathrm{ml}$. Sample solution was mixed with $2 \mathrm{ml}$ of the Hoechst dye solution (Hoechst $33258,0.5 \mu \mathrm{g} / \mathrm{ml}$ in TNE buffer). Fluorescence was measured using the excitation/emission wavelengths of 356/ 468. DNA content was calculated by interpolation in a calibration curve performed using standard DNA (DNA sodium salt from calf thymus from Sigma-Aldrich).

\section{Biomass RNA content}

RNA content of biomass was determined according to Benthin [38]. Briefly $5 \mathrm{mg}$ of lyophilized biomass were resuspended in $10 \mathrm{ml}$ of cold $0.7 \mathrm{M} \mathrm{HClO}_{4}$ and incubated for $5 \mathrm{~min}$. After incubation biomass was centrifuged $\left(8,000 \mathrm{rpm}, 10 \mathrm{~min}, 4^{\circ} \mathrm{C}\right)$, washed twice and resuspended in $10 \mathrm{ml} 0.3 \mathrm{M} \mathrm{KOH}$. Two $5 \mathrm{ml}$ aliquots of the resus- pended biomass were incubated at $37^{\circ} \mathrm{C}$ for $1 \mathrm{~h}$. After cooling $1 \mathrm{ml}$ cold $3 \mathrm{M} \mathrm{HClO}_{4}$ was added and samples were centrifuged in the same conditions. Supernatant was collected and the pellet washed twice with $1 \mathrm{ml} 0.5 \mathrm{M}$ $\mathrm{HClO}_{4}$. The 3 supernatants collected were mixed and absorbance measured at $260 \mathrm{~nm}$ in a quartz cuvette. The percentage $(\mathrm{w} / \mathrm{w})$ was calculated using $1 \mathrm{~A}_{260}$ unit $(1 \mathrm{~cm}$ path length): $0.038 \mathrm{mgRNA} / \mathrm{ml}$ and taking into account the sample dilution.

\section{Fab quantification by ELISA}

Fab amounts in soluble cell extracts and in culture broths were performed by means of a sandwich ELISA assay, as previously described [14]. For the quantification of the intracellular Fab cells were disrupted using a cell disruptor (One Shot. Constant Cell Distruption System LTD). Briefly, $5 \mathrm{ml}$ of $10 \mathrm{~g} / \mathrm{l}$ of lyophilized biomass resuspended in PBS buffer supplemented with $2 \%(\mathrm{w} / \mathrm{v})$ SDS, Complete $^{\mathrm{TM}}$ protease inhibitor cocktail (Roche) and $0.1 \% \beta \alpha$ mercaptoethanol, were disrupted at 2 Kbar of pressure in one shot. Fab analysis was performed as described for soluble cell extracts.

\section{Bioreactor culture broth concentrations}

Cell biomass was monitored by measuring the optical density at $600 \mathrm{~nm}\left(\mathrm{OD}_{600}\right)$. For cellular dry weight, a known volume of cultivation broth was filtered using preweighted filters; these were washed with two volumes of distilled water and dried to constant weight at $105^{\circ} \mathrm{C}$ for $24 \mathrm{~h}$. Samples for extracellular metabolite analyses were centrifuged at 10,000 rpm for $2 \mathrm{~min}$ in a microcentrifuge to remove the cells and subsequently filtered through 0.45 $\mu \mathrm{m}$-filters (Millipore type HAWP). Glucose, organic acids, ethanol and arabinitol were analyzed by HPLC (Series 1050, Hewlett Packard) with an ionic exchange column (Bio-Rad, Aminex HPX-87H). As mobile phase, $15 \mathrm{mM}$ sulphuric acid was used. The metabolites were detected (HP 1047A, Detector IR HP, Hewlett Packard) and quantified with the Empower-Profor Software.

\section{Identification of extracellular metabolites LC-MS analyses}

Extracellular metabolites were identified by means of LCMS. For this purpose, a volume of about $50 \mathrm{ml}$ of cleared culture supernatant was filtered through a $0.22 \mu \mathrm{m}$ Millipore filter. The analysis of filtered supernatants were performed on a Shimadzu Prominence HPLC with a UV/VIS detector coupled to a Mass Spectrometry detector Shimadzu 2010A equipped with an ESI (Electro Spray Ionization) interface operating at a wavelength of $210 \mathrm{~nm}$.

Metabolite compounds were separated on a $300 \mathrm{~mm} \times 7.8$ mm Aminex HPX-87H column (Biorad) using $0.15 \mathrm{mM}$ formic acid in miliQ water at $\mathrm{pH} 3$ as mobile phase in iso- 
cratic mode. The analyses were performed at a flow rate of $0.6 \mathrm{ml} / \mathrm{min}$ at room temperature using a $20 \mu \mathrm{l}$ injection volume.

\section{NMR analyses}

To identify the unknown extracellular metabolite by $\mathrm{NMR}$, one of the replica cultivation experiments under hypoxic conditions, was further used to perform a ${ }^{13} \mathrm{C}-$ labelling experiment with uniformly ${ }^{13} \mathrm{C}$-labeled glucose (Cortecnet), following a previously reported procedure [39]. In brief, isotopic labelling was achieved by feeding the bioreactor (at steady state conditions) with the medium containing about $10 \%(\mathrm{w} / \mathrm{w})$ of uniformly ${ }^{13} \mathrm{C}-$ labeled and $90 \%$ unlabeled substrate for one volume change. After that, a volume of $50 \mathrm{ml}$ of fresh sample from the chemostat culture was centrifuged at $4^{\circ} \mathrm{C}, 5000 \mathrm{rpm}$ for $5 \mathrm{~min}$. The supernatant was filtered through a $0.22 \mu \mathrm{m}$ Millipore filter, stored overnight at $-80^{\circ} \mathrm{C}$ and subsequently lyophilized. The lyophilisate residue was resuspended in a small volume of $\mathrm{D}_{2} \mathrm{O}$ prior to NMR analysis.

${ }^{13} \mathrm{C}$ NMR spectra of samples resuspended in $\mathrm{D}_{2} \mathrm{O}$ were analyzed using a Bruker Avance $500 \mathrm{MHz}$ spectrometer, operating at $125 \mathrm{MHz}$ for ${ }^{13} \mathrm{C}$, equipped with a cryoprobe and with about one hour accumulation. Spectra were referenced against an external standard in order to preserve sample recovery.

\section{Numerical calculations}

$\mathrm{Al}$ numerical calculations were performed using Matlab 2007b.

\section{Competing interests}

The authors declare that they have no competing interests.

\section{Authors' contributions}

MC performed bioreactor cultivations, cultivation experimental data acquisition and biochemical analyses, data calculation, analysis and interpretation of results and participated in drafting the manuscript. IT participated together with $\mathrm{MC}$ and $\mathrm{KB}$ in performing bioreactor cultivations, obtaining and analyzing bioreactor experimental data. KB participated in the experimental design of bioreactor cultivations, cultivation, cultivation analyses, arabinitol identification and interpretation of results. FS performed spectrometry analysis. DM participated in conceptual and experimental design of bioreactor cultivations. PF participated in the overall conceptual and experimental design of this study, interpretation of results and in drafting the manuscript. JA participated in the overall conceptual and experimental design of this study, data calculation, analysis and interpretation of results and in drafting the manuscript. All authors revised and approved the final manuscript.

\section{Additional material}

\section{Additional file 1}

Measured chemical elements in the biomass. Major chemical elements measured in the biomass for each strain at the different experimental conditions ( $\% \mathrm{O}_{2}$ in the inlet air: $\left.21,11,8\right)$. Data given as percentage of dry weight.

Click here for file

[http://www.biomedcentral.com/content/supplementary/14752859-8-65-S1.PDF]

\section{Additional file 2}

Calculated C-mol formula for each biomass component. Calculated Cmol formulas of the molecular biomass components at the different experimental conditions $\left(\% \mathrm{O}_{2}\right.$ in the inlet air: $\left.21,11,8\right) .{ }^{*}$ Data from Lange and Heijnen 2001 [11] for S. cerevisiae.

Click here for file

[http://www.biomedcentral.com/content/supplementary/14752859-8-65-S2.PDF]

\section{Additional file 3}

HPLC chromatogram of a hypoxic culture broth. Chromatogram with the unknown peak at retention time of 11.5 min in a HPLC. Hewlett Packard 1050 Biorad Aminex HPX-87C ion-exchange resin column. Click here for file

[http://www.biomedcentral.com/content/supplementary/14752859-8-65-S3.PDF]

\section{Additional file 4}

NMR spectrum of a hypoxicculture broth. 13 C NMR spectrum of a $\mathrm{D}_{2} \mathrm{O}$-resuspended lyophilised hypoxic culture broth sample in a Bruker Avance $500 \mathrm{MHz}$ spectrometer.

Click here for file

[http://www.biomedcentral.com/content/supplementary/14752859-8-65-S4.PDF]

\section{Acknowledgements}

This work has been supported by the Spanish program on Chemical Process Technologies (project CTQ2007-60347/PPQ) and the Complementary Actions Plan (project BIO2005-23733-E) supporting the European Science Foundation EuroSCOPE programme (project GENOPHYS), as well as the Generalitat de Catalunya (2005-SGR-00698). Amino acid and lipids compositional analyses were performed by the Scientific-Technical Services (SCT) facilities of the Universitat de Barcelona, Spain. The authors thank SCT personnel for critical discussion of the experimental data.

\section{References}

I. Lee SY, Lee DY, Kim TY: Systems biotechnology for strain improvement. TRENDS Biotechnol 2005, 23:349-358.

2. Graf A, Dragosits M, Gasser B, Mattanovich D: Yeast systems biotechnology for the production of heterologous proteins. FEMS Yeast Res 2009, 9:335-348.

3. Covert MW, Knight EM, Reed JL, Herrgard MJ, Palsson BO: Integrating high-throughput and computational data elucidates bacterial networks. Nature 2004, 429:92-96.

4. Forster J, Famili I, Fu PC, Palsson BO, Nielsen J: Genome-scale reconstruction of the Saccharomyces cerevisiae metabolic network. Genome Res 2003, 13:244-253.

5. Feist AM, Palsson BO: The growing scope of applications of genome-scale metabolic reconstructions using Escherichia coli. Nat Biotechnol 2008, 26:659-667. 
6. Nookaew I, Jewett MC, Meechai A, Thammarongtham C, Laoteng K, Cheevadhanarak S, Nielsen J, Bhumiratana S: The genome-scale metabolic model iIN800 of Saccharomyces cerevisiae and its validation: a scaffold to query lipid metabolism. BMC Systems Biol 2008, 2:7I.

7. Feist AM, Herrgård MJ, Thiele I, Reed JL, Palsson BØ: Reconstruction of biochemical networks in microorganisms. Nat Rev Microbiol 2009, 7:129-143.

8. Schmidt K, Norregaard LC: Quantification of intracellular metabolic fluxes from fractional enrichment and ${ }^{13} \mathrm{C}-{ }^{13} \mathrm{C}$ coupling constraints on the isotopomer distribution in labeled biomass components. Metabolic Eng 1999, I:166-179.

9. Fredlund E, Blank LM, Schnurer J, Sauer U, Passoth V: Oxygen- and glucose-dependent regulation of central carbon metabolism in Pichia anomala. Appl Environ Microbiol 2004, 70:5905-59lI.

10. Dragosits M, Stadlmann J, Albiol J, Baumann K, Maurer M, Gasser B, Sauer M, Altmann F, Ferrer P, Mattanovich D: The effect of temperature on the proteome of recombinant Pichia pastoris. J Proteome Res 2009, 8(3): $1380-1392$.

II. Lange HC, Heijnen J]: Statistical reconciliation of elemental and molecular biomass composition of Saccharomyces cerevisiae . Biotechnol Bioeng 75:334-344.

12. Noorman H, Romein B, Luyben K, Heijnen J: Classification, error detection, and reconciliation of process information in complex biochemical systems. Biotechnol Bioeng 1996, 49:364-76.

13. Stephanopoulos G, Aristidou A, Nielsen J: Metabolic engineering Principles and methodologies San Diego, CA: Academic Press; 1998.

14. Baumann K, Dragosits M, Graf A, Maurer M, Gasser B, Stadlmann J, Altmann F, Mattanovich D, Ferrer P: A multilevel study of heterologous protein production in Pichia pastoris under different oxygen conditions as a knowledge base for strain improvement. New Biotechnol 2009, 25S:S330.

15. Gasser B, Maurer M, Gach J, Kunert R, Mattanovich D: Engineering of Pichia pastoris for improved production of antibody fragments. Biotechnol Bioeng 2006, 94:353-36I.

16. Baumann K, Maurer M, Dragosits M, Cos O, Ferrer P, Mattanovich D: Hypoxic fed-batch cultivation of Pichia pastoris increases specific and volumetric productivity of recombinant proteins. Biotechnol Bioeng 2008, 100:177-183.

17. Schutter K, Lin Y, Tiels P, Van Hecke A, Glinka S, Weber-Lehmann J, Rouze $P$, Peer $Y$ van de, Callewaert N: Genome sequence of the recombinant protein production host Pichia pastoris . Nat Biotechnol 2009, 27:56I-569.

18. Mattanovich D, Graf A, Stadlmann J, Dragosits M, Redl A, Maurer M, Kleinheinz M, Sauer M, Altmann F, Gasser B: Genome, secretome and glucose transport highlight unique features of the protein production host Pichia pastoris . Microb Cell Fact 2009, 8:29.

19. Unnikrishnan I, Miller S, Meinke M, LaPorte DC: Multiple positive and negative elements involved in the regulation of expression of GSYI in Saccharomyces cerevisiae. I Biol Chem 2003, 278:26450-26457.

20. Goffeau A, Barrell BG, Bussey H, Davis RW, Dujon B, Feldmann H, Galibert F, Hoheisel JD, Jacq C, Johnston M, Louis EJ, Mewes HW, Murakami Y, Philippsen P, Tettelin P, Oliver SG: Life with $\mathbf{6 0 0 0}$ Genes. Science 1996, 274:546-567.

21. Walker GM: Yeast physiology and biotechnology. New York: Wiley \& Sons; 2000.

22. Cregg JM, Shen S, Johnson M, Waterham HR: Classical genetic manipulation. Meth Mol Biol 1989, I03:17-26.

23. Wang N, Stephanopoulos G: Application of macroscopic balances to the identification of gross measurement errors. Biotechnol Bioeng 1983, 25:2177-2208.

24. Noorman H, Romein B, Luyben K, Heijnen J: Classification, error detection, and reconciliation of process information in complex biochemical systems. Biotechnol Bioeng 1996, 49:364-376.

25. Heijden R van der, Romein B, Heijnen J, Hellinga C, Luyben K: Linear constraint relations in biochemical reaction systems: I. Classification of the calculability and the balanceability of conversion Rates. Biotechnol Bioeng 1994, 43:3-10.

26. Heijden R van der, Romein B, Heijnen J, Hellinga C, Luyben K: Linear constraint relations in biochemical reaction systems: II. Diagnosis and estimation of gross errors. Biotechnol Bioeng 1994, 43: II-20.

27. Heijden RTJM van der, Romein B, Heijnen JJ, Hellinga C, Luyben KCAM: Linear constrain relations in biochemical reaction systems III. Sequential application of data reconciliation for sensitive detection of systematic errors. Biotechnol Bioeng 1994 , 44:78I-79I.

28. Bellinger $Y$, Larher $F: A^{13} \mathbf{C}$ comparative nuclear magnetic resonance study of organic solute production and excretion by the yeasts Hansenula anomala and Saccharomyces cerevisiae in saline media. Can J Microbiol I988, 34:605-6I.

29. Tokuoka K: Sugar and salt-tolerant yeasts. J Appl Microbiol 1993 74: $101-110$.

30. Passoth V, Fredlund E, Druvefors U, Schnürer J: Biotechnology, physiology and genetics of the yeast Pichia anomala. FEMS Yeast Res 2006, 6:3-13.

31. Gancedo C, Serrano R: Energy-yielding metabolism. In The Yeasts Edited by: Rose A, Harrison J. New York: Academic Press; 1989:206-259.

32. Moore $\mathrm{S}$, Spackman $\mathrm{H}$, Stein $\mathrm{H}$ : Chromatography of amino acids on sulfonated polystyrene resins. Anal Chem 30(7): I I85-I I 90.

33. Herbert D, Phipps PJ, Strange RE: Chemical analysis of microbial cells. Methods in Microbiology 1971, 5b:209-344.

34. Smolders GJF, Meij J van der, van Loosdrecht MCM, Heijnen JJ: Stoichiometric model of the aerobic metabolism of the biological phosphorus removal process. Biotechnol Bioeng 1994, 44:837-848

35. Roustan JL, Sablayrolles JM: Trehalose and glycogen in winemaking yeasts: methodological aspects and variability. Biotechnol Lett 2002, 24:1059-1064.

36. Hara A, Radin NS: Lipid extraction of tissues with low-toxicity solvent. Anal Biochem 1978, 90:420-426.

37. De Mey M, Lequeux G, Maertens J, De Maeseneire S, Soetaert W, Van Damme E: Comparison of DNA and RNA quantification methods suitable for parameter estimation in metabolic modelling of microorganisms. Anal Biochem 2006, 353:198-203.

38. Benthin S, Nielsen J, Villadsen J: A simple and reliable method for the determination of cellular RNA content. Biotechnol Tech 1991, 5:39-42.

39. Solà A, Maaheimo H, Yloönen K, Ferrer P, Szyperski T: Amino acid biosynthesis and metabolic flux profiling of Pichia pastoris. Eur Jiochem 2004, 27 I:2462-2470.
Publish with BioMed Central and every scientist can read your work free of charge

"BioMed Central will be the most significant development for disseminating the results of biomedical research in our lifetime. "

Sir Paul Nurse, Cancer Research UK

Your research papers will be:

- available free of charge to the entire biomedical community

- peer reviewed and published immediately upon acceptance

- cited in PubMed and archived on PubMed Central

- yours - you keep the copyright
BioMedcentral 